\title{
INFRARED LUMINESCENCE IN Er AND Er+O IMPLANTED 6H SiC
}

\author{
A. KoZANECKI \\ Institute of Physics, Polish Academy of Sciences \\ Al. Lotników 32/46, 02-668 Warsaw, Poland \\ W. Jantscil, W. Heis, G. Prechtl \\ Johannes Kepler Universität, 4040, Linz, Austria
}

B.J. Sealy and C. Jeynes

Surrey Centre for Research in Ion Beam Applications, University of Surrey Guildford, Surrey, GU2 5XH, UK

\begin{abstract}
Photoluminescence in the neighbourhood of $1.54 \mu \mathrm{m}$ due to the ${ }^{4} I_{13 / 2}-{ }^{4} I_{15 / 2}$ intra- 4 -shell transitions of $\mathrm{Er}^{3+}$ ions in $6 \mathrm{H} \mathrm{SiC}$ is studied. Effects of oxygen coimplantation is also investigated. No difference in the photoluminescence spectra of $\mathrm{Er}$ only and $\mathrm{Er}+\mathrm{O}$ implanted $\mathrm{SiC}$ was found. It is concluded that the emission around $1.54 \mu \mathrm{m}$ in $\mathrm{SiC}: \mathrm{Er}$ originates from erbium-oxygen complexes, which are formed as a result of thermal annealing.
\end{abstract}

PACS numbers: $61.72 . \mathrm{Ww}, 71.55 .-\mathrm{i}, 78.55 .-\mathrm{m}$

The research interest in erbium doped semiconductors is growing rapidly [1], because $\mathrm{Er}^{3+}$ ions exhibit luminescence around $1.54 \mu \mathrm{m}$ originating in the ${ }^{4} I_{13 / 2} \rightarrow$ ${ }^{4} I_{15 / 2}$ electronic transitions within the $4 f$ shell. This wavelength corresponds to the minimum absorption of silica-based fibers, making Er-doped light sources and amplifiers promising for applications in optical telecommunications.

While many Er-doped semiconductors have been studied to date, only a few reveal $1.54 \mu \mathrm{m}$ emission at $300 \mathrm{~K}$. Favennec et al. [2] have observed that the quenching processes of the $4 f-4 f$ photoluminescence (PL) of $\mathrm{Er}^{3+}$ ions become less effective with the increase of the semiconductor band gap. Attempts to increase the emission efficiency of erbium in Si and GaAs with oxygen codoping were quite successful [3-5], however, the intensity of light from Er+O doped Si and GaAs electroluminescent diodes has been still too low for any practical applications. Once again the relatively narrow band gaps of semiconductors, particularly in case of $\mathrm{Si}$, appeared to be the dominant parameter affecting excitation and relaxation of the $4 f$-shell. All these observations point to the necessity to use wide band gap semiconductors, like $\mathrm{SiC}, \mathrm{GaN}, \mathrm{AlN}$, etc., as hosts, to receive the efficient $4 f-4 f$ 
emission of $\mathrm{Er}^{3+}$ ions at $300 \mathrm{~K}$ [1]. This conclusion was confirmed, i.e., by Choyke et al. [6] who showed that the integrated $4 f-4 f \mathrm{PL}$ intensity of $\mathrm{Er}^{3+}$ from $1.49 \mu \mathrm{m}$ to $1.64 \mu \mathrm{m}$ in different $\mathrm{SiC}$ polytypes is almost constant up to about $400 \mathrm{~K}$.

In this paper the results of a study of the $4 f-4 f$ PL due to ${ }^{4} I_{13 / 2} \rightarrow{ }^{4} I_{15 / 2}$ electronic transitions of $\mathrm{Er}^{3+}$ ions around $1.54 \mu \mathrm{m}$ in $6 \mathrm{H} \mathrm{SiC}$ are presented. First experimental data on $\mathrm{SiC}: \mathrm{Er}$ intentionally codoped with oxygen are also shown.

Samples of $6 \mathrm{H} \mathrm{SiC} \mathrm{crystal} \mathrm{doped} \mathrm{with} \mathrm{nitrogen} \mathrm{to} \mathrm{a} \mathrm{concentration} \mathrm{of}$ $10^{18} \mathrm{~cm}^{-3}$ were implanted at $300 \mathrm{~K}$ with $800 \mathrm{keV} \mathrm{Er}+$ ions. Some samples were implanted with $1 \mathrm{MeV} \mathrm{Er}^{+}$ions at $350^{\circ} \mathrm{C}$ to avoid amorphization of the surface layer. The $\mathrm{Er}$ ion doses were $10^{13}, 10^{14}$, and $2 \times 10^{15} \mathrm{~cm}^{-2}$. Oxygen ions were implanted into SiC:Er to doses of $1-5 \times 10^{15} \mathrm{~cm}^{-2}$ and at an energy of $125 \mathrm{keV}$ to produce the O-impurity profiles overlapping those of erbium.

The implanted samples were annealed in a nitrogen gas flow at temperatures $1000-1500^{\circ} \mathrm{C}$ for half an hour. PL was excited with a $50 \mathrm{~mW}$ power of a $355 \mathrm{~nm}$ line of an $\mathrm{Ar}^{+}$laser and measured within the 1.48-1.6 $\mu \mathrm{m}$ spectral range. SiC samples were also analysed using Rutherford backscattering (RBS) to follow the redistribution of the Er impurity profile as a result of high temperature annealing.

The $4 f-4 f$ emission of $\mathrm{Er}^{3+}$ near $1.54 \mu \mathrm{m}$ could be observed only in samples annealed at $1500^{\circ} \mathrm{C}$. Figure 1 shows the ${ }^{4} I_{13 / 2} \rightarrow{ }^{4} I_{15 / 2}, 1.54 \mu \mathrm{m}$ PL spectra of $6 \mathrm{H} \mathrm{SiC}$ at temperatures ranging from $1.4 \mathrm{~K}$ to $293 \mathrm{~K}$. At $1.4 \mathrm{~K}$, the dominant line at $1.534 \mu \mathrm{m}$ is accompanied with a variety of much weaker lines located on the low as well as on the high energy side of the spectra. At elevated temperatures the intensity of the high energy lines increases on the expense of the dominant line at $1.534 \mu \mathrm{m}$. It suggests that they are due to the radiative transitions from the excited levels of the ${ }^{4} I_{13 / 2}$ multiplet. The integrated PL intensity from 1.5 to $1.6 \mu \mathrm{m}$ remains constant up to $200 \mathrm{~K}$. At temperatures above $200 \mathrm{~K}$ the intensity decreases and at room temperature it is by a factor of 2 lower than at $1.4 \mathrm{~K}$, in some disagreement with the results of Choyke et al. [6] and Yoganathan et al. [7].

As $\mathrm{SiC}$ crystals are grown at very high temperature and also annealing temperatures exceed $1500^{\circ} \mathrm{C}$, the contamination of $\mathrm{SiC}$ samples with oxygen either during the growth or annealing is highly probable. The presence of oxygen would affect the structure of Er emitting centres, like in Si:Er [4], because of the very high chemical affinity of erbium element to oxygen. To check a possible role of oxygen in forming the emitting centres, some $\mathrm{SiC}$ samples implanted at $350^{\circ} \mathrm{C}$ with $1 \mathrm{MeV} \mathrm{Er}+$ ions were coimplanted with $\mathrm{O}^{+}$ions and annealed in the same way as samples doped solely with Er. Once again the $4 f-4 f$ emission of $\mathrm{Er}^{3+}$ was observed only after annealing at $1500^{\circ} \mathrm{C}$.

The PL spectra at $120 \mathrm{~K}$ of $\mathrm{Er}$ and $\mathrm{Er}+\mathrm{O}$ implanted samples are compared in Fig. 2. It is seen that there is no difference in the overall shape of the spectra. This very close similarity has been noticed for all temperatures between $1.4 \mathrm{~K}$ and $300 \mathrm{~K}$. It gives strong support to the conclusion that in $6 \mathrm{H} \mathrm{SiC}$ the dominant $\mathrm{Er}$ emitting centres are complexes involving oxygen. Some broadening of the PL lines in the spectrum of $\mathrm{SiC}: \mathrm{Er}: \mathrm{O}$ is most probably due to the higher concentration of residual defects than in SiC:Er.

We have found, using RBS, that the implanted Er atoms segregate at the surface of $\mathrm{SiC}$ samples after annealing at temperatures exceeding $1300^{\circ} \mathrm{C}$ (Fig. 3). 


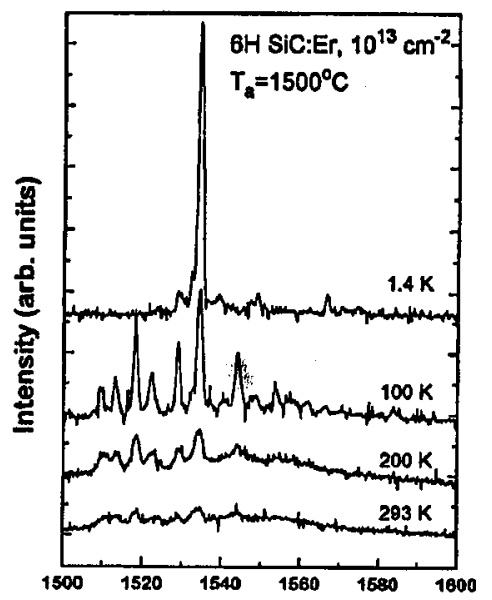

Fig.1 Wavelength (nm)

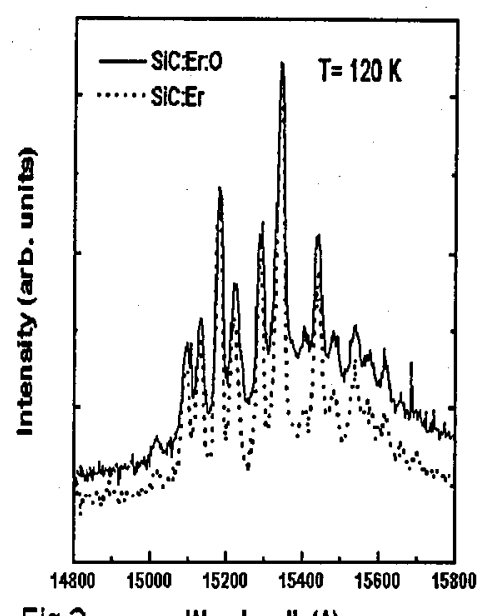

Fig.2. Wavelenglh (A)

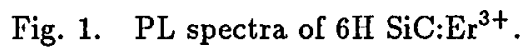

Fig. 2. Comparison of the PL spectra at $120 \mathrm{~K}$ of SiC:Er and SiC:Er:O.

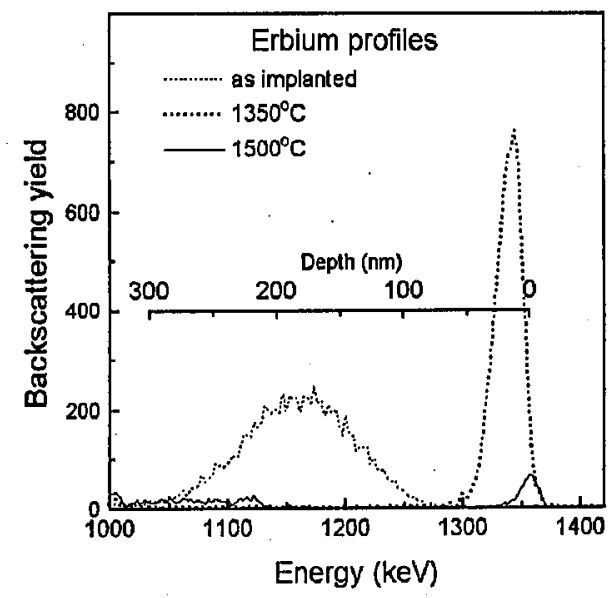

Fig. 3. Er impurity profiles in as-implanted and annealed SiC. Er dose $-2 \times 10^{15} \mathrm{~cm}^{-2}$.

An analysis shows that approximately $17 \%$ of the total number of $\mathrm{Er}$ atoms is lost as a result of annealing at $1350^{\circ} \mathrm{C}$, most probably due to the formation of some volatile compounds of $\mathrm{Er}, \mathrm{Si}, \mathrm{C}$ and $\mathrm{O}$. Annealing at $1500^{\circ} \mathrm{C}$ causes more than $95 \%$ loss of the number of $\mathrm{Er}$ atoms (Fig. 3). As a result, the most intense $4 f-4 f$ emission of $\mathrm{Er}^{3+}$ was observed in samples implanted with a dose of $10^{13} \mathrm{~cm}^{-2}$, too low to amorphize the surface layer.

Our data suggest that temperature quenching of the $4 f-4 f \mathrm{PL}$ of $\mathrm{Er}^{3+}$ in $\mathrm{SiC}$ is more efficient than in previously published results. 
There are two major differences in the experimental conditions in this work and in experiments of Choyke et al. [6], and Yoganathan et al. [7]: in our work the maximum annealing temperature was $1500^{\circ} \mathrm{C}$, in comparison with $1700^{\circ} \mathrm{C}$ used by them. Therefore the concentration of residual defects which may act as nonradiative recombination centres is probably much higher in our samples. The second difference is nitrogen donor concentration, being in our crystal higher by a factor of two. According to the observation of Yoganathan et al. [7] more efficient quenching may be expected, i.e., due to Auger processes. This issue has not been studied yet. The spectra presented in Fig. 1 are the same like those presented in papers [6] and [7], in spite of the different implant and annealing conditions, suggesting the same structure of the emitting centres. With respect to our observation they are most probably complexes involving erbium and oxygen atoms.

The experimental data presented here suggest that some Er+O complexes are responsible for the emission at $1.54 \mu \mathrm{m}$ in SiC:Er. These complexes are formed as a result of annealing at temperatures exceeding $1500^{\circ} \mathrm{C}$. RBS analysis shows that most of $\mathrm{Er}$ atoms diffuse out of $\mathrm{SiC}$ and are lost due to the formation of volatile compounds. It clearly shows that implantation and annealing conditions have to be elaborated to maximize the emission at $1.54 \mu \mathrm{m}$ from SiC:Er.

\section{Acknowledgment}

This work has been supported in part by the Committee for Scientific Research (grant No. PB 1027/T11/96/10).

\section{References}

[1] Rare Earth Doped Semiconductors II, Eds. S. Coffa, A. Polman, R.N. Schwartz, in series Mater. Res. Soc. Symp. Proc., Vol. 422, Materials Res. Soc., Pittsburgh (PA) 1996.

[2] P.N. Favennec, H. L'Haridon, D. Mountonnet, M. Salvi, M. Gauneau, in Ref. [1], p. 181.

[3] R. Serna, E. Snoeks, G.N. van den Hoven, A. Polman, J. Appl. Phys. 75, 2644 (1994).

[4] H. Przybyliniska, W. Jantsch, Yu. Suprun-Belevitch, M. Stepikhova, L. Palmetshofer, G. Hendorfer, A. Kozanecki, R.J. Wilson, B.J. Sealy, Phys.Rev. B 54, 2532 (1996).

[5] K. Takahei, A. Taguchi, J. Appl. Phys. 77, 1735 (1995).

[6] W.J. Choyke, R.P. Devaty, L.L. Clemen, M. Yoganathan, G. Pensl, Ch. Hassler, Appl. Phys. Lett. 66, 562 (1995).

[7] M. Yoganathan, W. Choyke, R.P. Devaty, G. Pensl, J.A. Edmond, in Ref. [1], p. 339. 